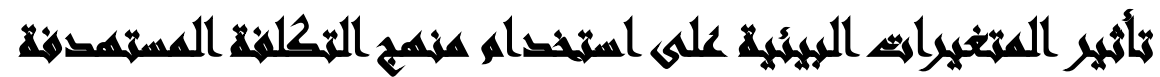

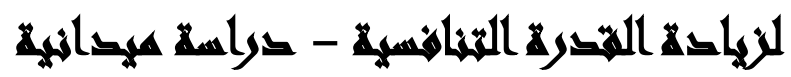

\section{$[1, r]$}

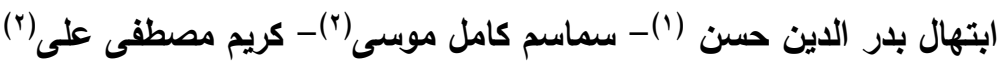

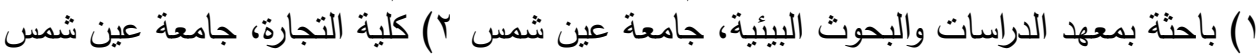

\section{المستخلئ}

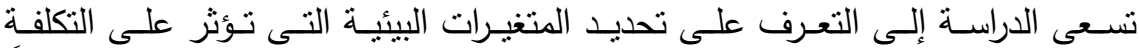

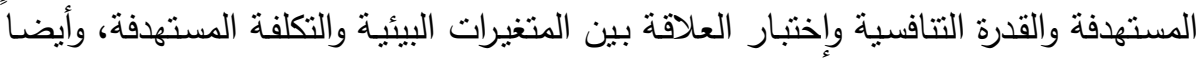

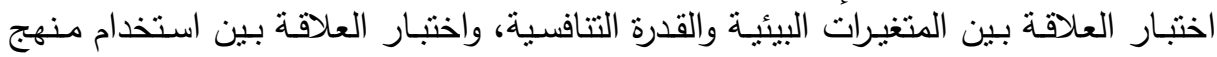

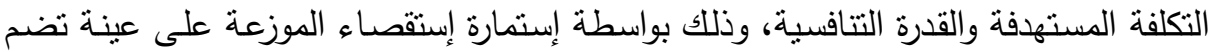

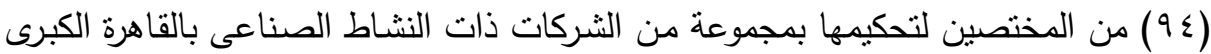

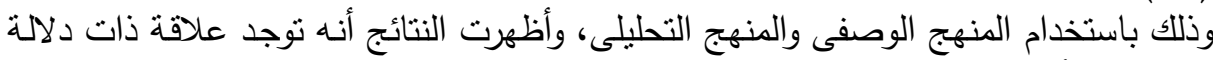

إحصائية لتأثير المتغيرات البيئية على استخدام منهج التكلفة المستهدفة لزيادة القدرة التتافسية.

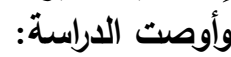

1-الاهتمام بتخفيض التكاليف مع الحفاظ على الجودة في كافة مراحل العملية الإنتاجية .

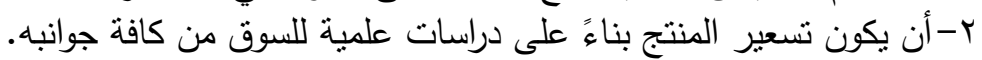
r-القيام بدراسة المعوقات والمشكلات التي تحول دأل دون تطبيق منهج التكلفة المستهدفة،

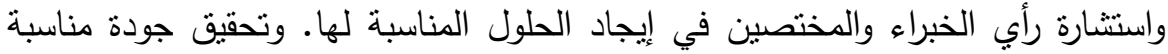

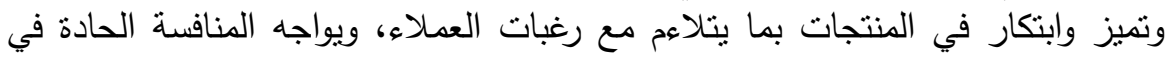
الأسواق.

\section{المهبه}

ضغطت المنافسة العالمية في عصرنا الحالي على المنشآت الصناعية لكي تتجه لاستخدام مناهج حديثة فى التسعبر بهرف تحقيق موقع نتافسي مميز يمكن تلاك المنشآت من كسب الأسواق

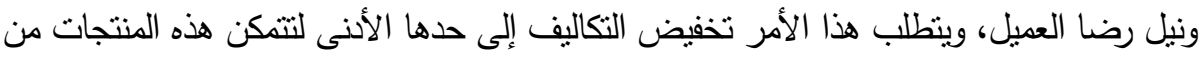


المنافسة من حبث النوعية والسعر في الأسواق المحلية والعالمية، لذا أصبح تطوير أنظمة التكاليف أمراً ضرورياً ينبغي التعامل معه بموضوعية وعلمية للوصول إلى قرارات تسعير رشيدة.

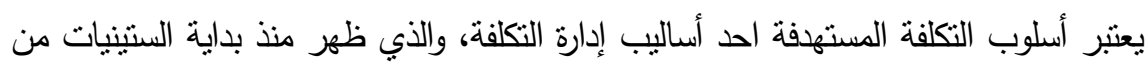

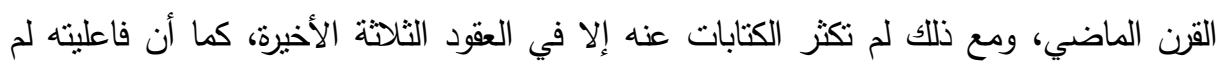

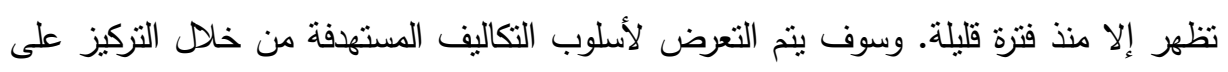

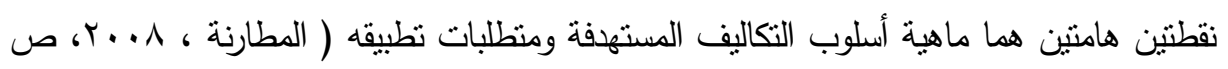

تواجه المنظمات اليوم العديد من المتغيرات التي تتصف بالتغير والتعقيد إضافة إلى عدم الوضوح والاستقرار، فخلال العثرين السنة الماضية رسمت الأحداث المنسارعة والمتلاحقة صورة

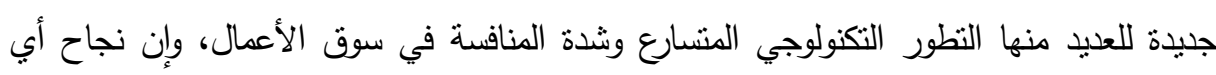
منثأة يعتمد بثكل أساسي على قدرة إدارتها على تفسير وتحليل المتغيرات البيئية المحيطة ودقة لئة

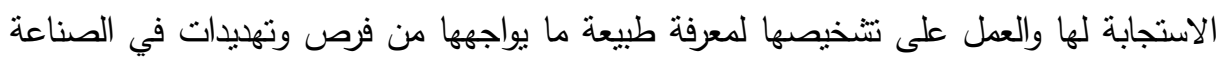
التي تتنمي إليها والتعرف على محدات النجاح عند النعامل مع العملاء والموردين والمنافسين

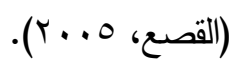

وحيث توصف الإحداث البيئية ذات التأثير في المنظمة (بالتغيرات التكنولوجية - التغير

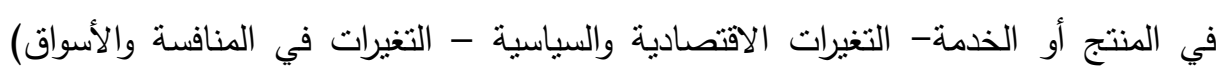

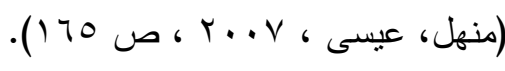

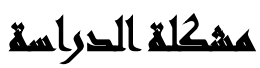

تتمنل مشكلة البحث فى أن التطورات الاقتصادية المتلاحقة والمتمثلة فى الإنفتاح الاقتصادي، والنطور المتلاحق فى البيئة الصناعية الحديثة، جعلت الواقع العلمى لبيئة

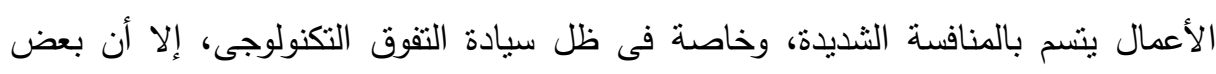

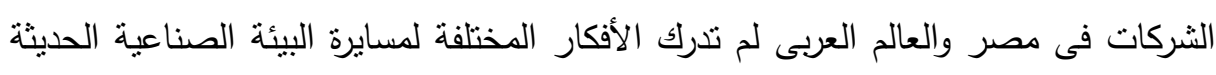

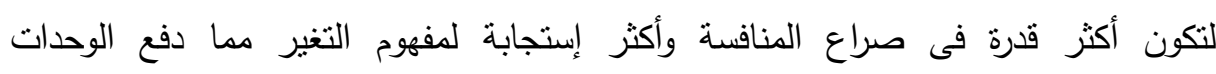

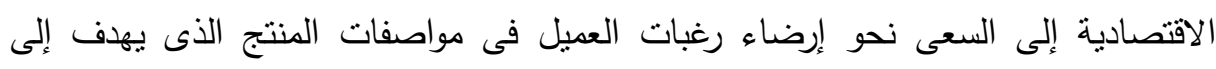


إقتتاه، وهذا يستلزم السرعة فى تطوير وتصميم المنتجات بالثكل الذى يحقق الجودة فى الأداء، وبأقل تكلفة ممكنة.

ولقد تزايد اهنمام المنظمات الدولية بضرورة تعامل الدول ومنظمات الأعمال بالدولة الواحدة

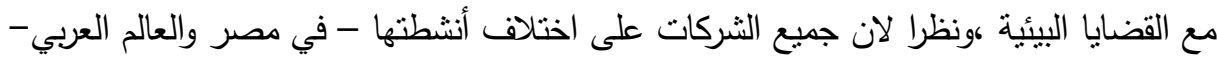
تتشه احتدام المنافسة بين الثركات الصناعية الكبرى بهذف إحكام السيطرة على السوق العالمية،

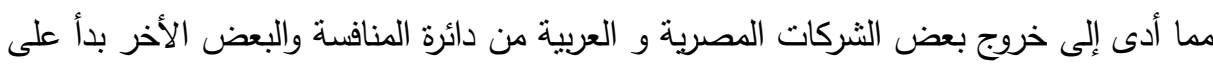

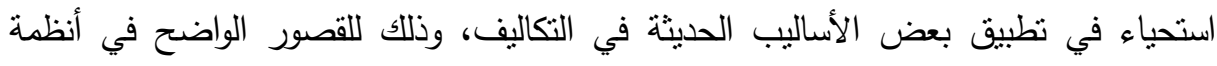
التكاليف التقليدية وعدم قدرتها على مواجهة تلك المنافسات الثديدة نظرا لعدم قدرتها على تحقيق الرقابة اللازمة على التكاليف والوصول إلى خفض حقيقي وملموس في التكلفة، كل ذلك وغيره كان مناخا مناسبا لتنبى وتطبيق أسلوب التكاليف المستهدفة باعنباره الأسلوب الأكثر فاعلية لدعم المزايا النتافسية وتحقيق تخفيض ملموس في التكاليف سواء في مرحلة تصميم المنتجات أو في المراحل التالية لذلك. ومن خلال اطلاع الباحثة على الدراسات السابقة للمتغيرات البيئية والتكلفة المستهدفة لدعم القدرة التتافسية ، حيث توصلت الدراسات لعدة نتائج أهمها: استخدام أساليب حديثة لتخفيض التكلفة بما لا يؤثر على الجودة ويؤدى ذلك لتطوير

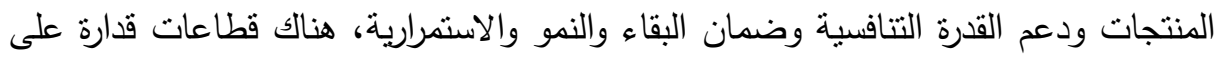
توفير المقومات التى تمكنها من تطبيق أسلوب التكلفة المستهدفة فى ظل المتغيرات البيئية

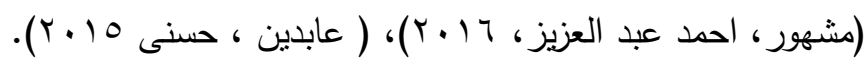




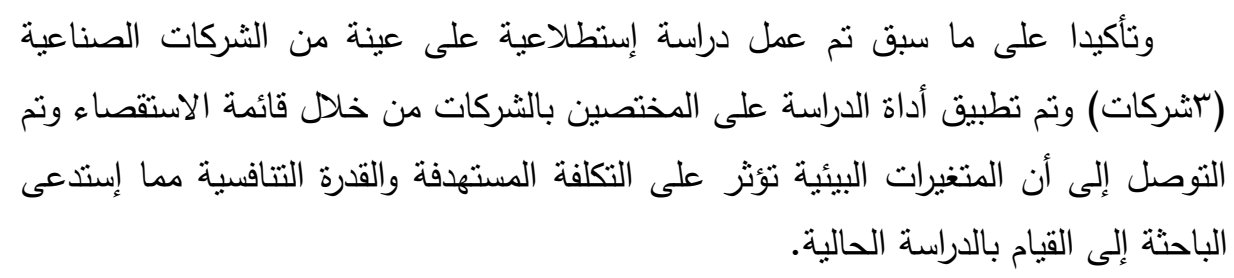

\section{أسئلة الترواسلة}

تتمثل مشكلة البخث فى الاجابة على عدة تساؤلان أهمها ما يلي:

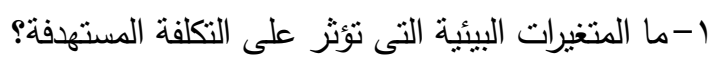

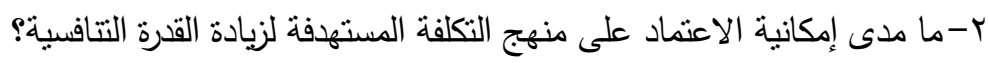

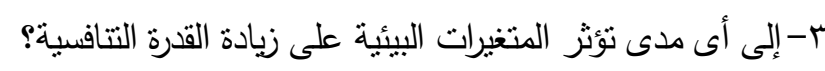
ع-ما مدى دراسة نأثير التغيرات البيئية المحيطة بالمنظهة سواء الداخلية أو الخارجية على لئى

التكلفة المستهدفة والقدرة التتافسية؟ دانئ

\section{أهساهثب الصواسما}

ا ـ تحديد المتغيرات البيئية التي تؤثر على التكلفة المستهدفة والقدرة التنافسية.

r. اختبار العلاقة بين المتغيرات البيئية والتكلفة المستهدفة. r. اختبار العلاقة بين المتغيرات البيئية والقدرة التنافسية. ع. اختبار العلاقة بين استخدام التكلفة والقدرة التتافسية.

\section{أهمية القورسمة}

الأهمية العلمية: تأتى الأهمية العلمية من خلد ندرة الكتابات والبحوث العلمية التى نتاولت

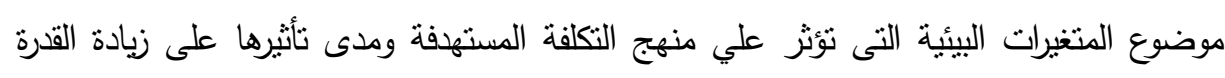

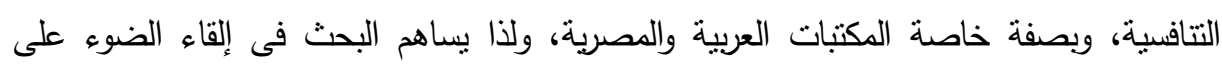

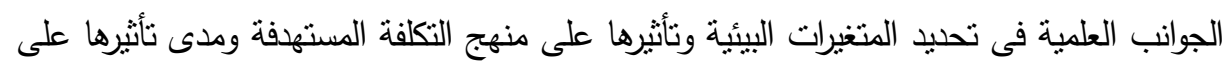
زيادة القرة النتافسية. 
الأهمية العملية: فى ظل المتغيرات البيئية التى تواجه المؤسسة، فإن التعامل مع هذه البيئة

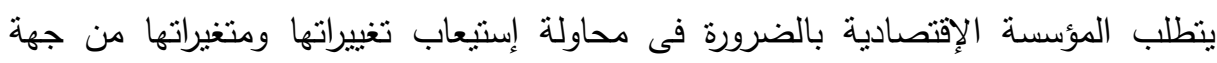

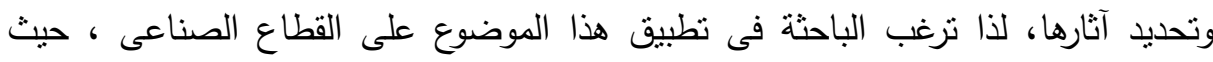
يمكن بذلك مواجهة القطاع الصناعى للمنافسة التى تواجهه اليوم عن طريق زيادة القدرة

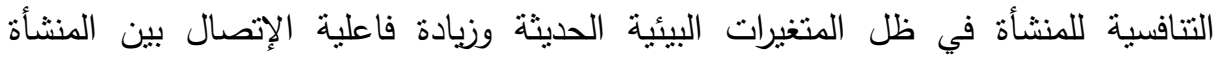
وعملائها ومورديها.

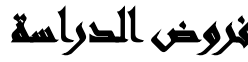

فرض أول: توجد علاقة جوهرية دلالة إحصائية بين المتغيرات البيئية والتكلفة المستهدفة. فرض ثانى: نوجد علاقة جوهرية دلالة إحصائية بين المتغيرات البيئية والقرة النتافسية. فرض ثالث: نوجد علاقة جوهرية بين إستخدام التكلفة المستهافة والقدرة والتتافسية.

\section{مشوض الكوراسمة}

الحدود المكانية للبحث: شركات صناعية بالقاهرة الكبرى [ثركة القاهرة لتكرير البترول وشركة المسابك الحديثة ( محمد يحيى سعد الدين العبد وشركاه ) وشركة المصرية الأسبانية لتكنولوجيا المعادن والثركة الثرقية الهندسية والتجارة و شركة السحيمى للمعدات البحرية وشركة الحوامدية لصناعة السكر].

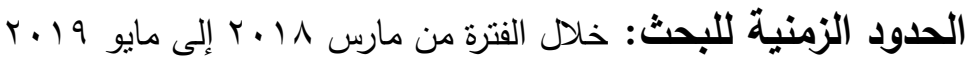

\section{هنهمج التراسه}

$$
\text { • • الأسلوب الوصفى. }
$$




\section{التوراساهي الماريهة}

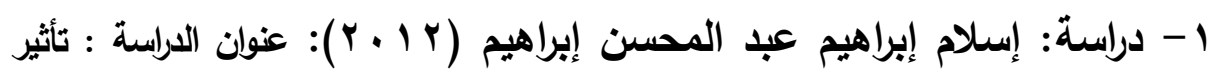

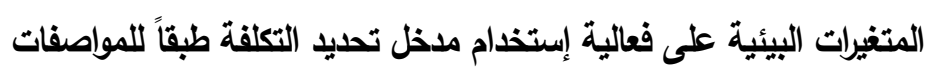

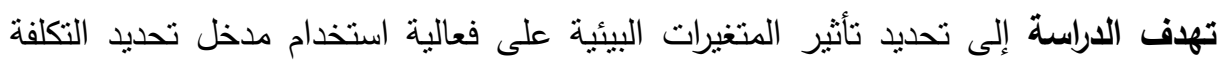

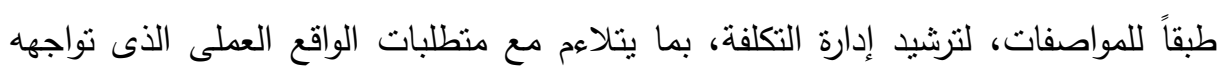

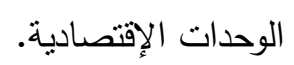

تأثير المتغيرات البيئية على سلوك المستهلك، وعلى قرار الثـراء، من حيث تغيير

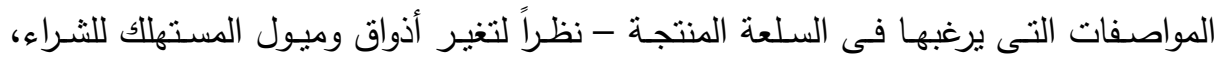

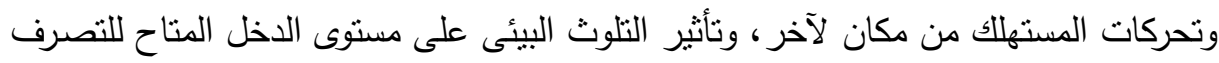

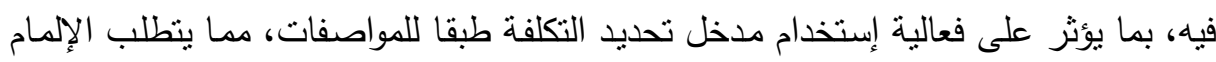

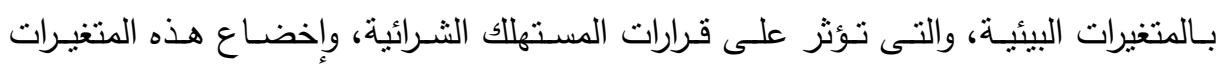

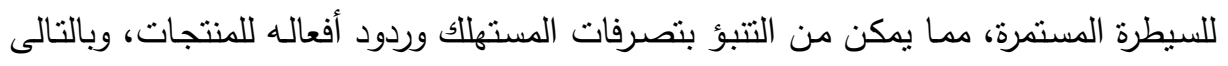

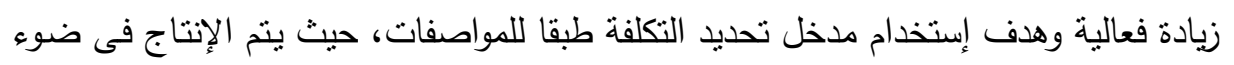

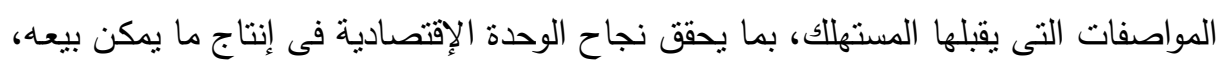
وتزداد قدرتها على الإسترار فى دنيا الأعمال فى ظل بيئة تنافسية حادة.

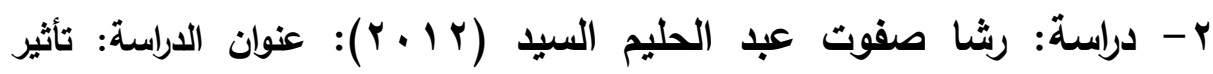
المتغيرات على قرارات الإستثمار فى البورصة المصرية.

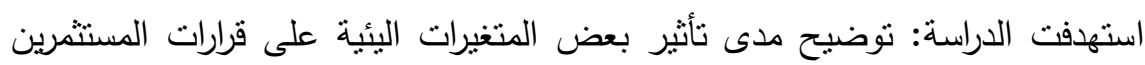

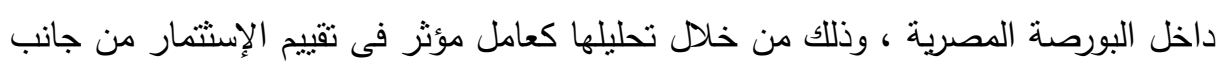

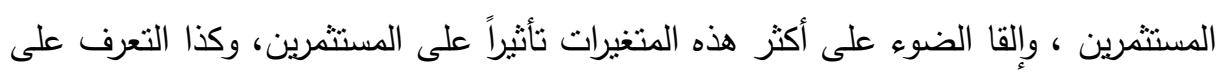

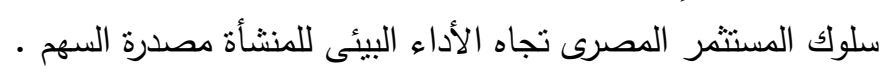

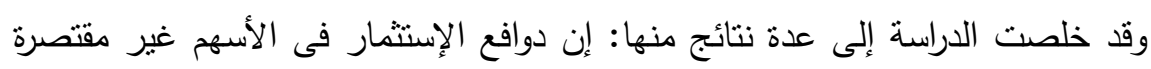

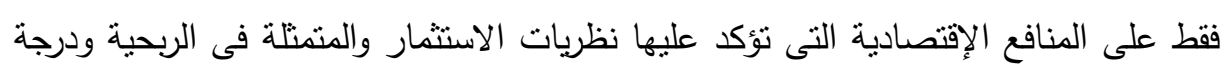
المخاطرة ومستوى السيولة، ولكن إضافة إلى ذلك فهناك دوافع أخرى مستمدة من منافع بيئية 
ونفسية وإجتماعية ووطنية ودينية تساعد فى تحريك الفرد عند إنخاذه لقراراته الاستثمارية ، كما أن نقص المعلومات البيئية التى يتم نشرها فى بورصة الأوراق المالية يؤدى إلى عدم قدرة المستثر على التقييم الدقيق لمستوى أداء الوحدات الاقتصادية.

Cheraghu, et. al., (2012) ب

Gaining Competitive Advantage through Marketing Strategies in Container Terminal: A Case Study on Shahid Rajaee Port in Iran

هدفت الدراسة إلى التعرف على العوامل المؤثزة فى تحقيق والحصول على ميزة تتافسية من خلال إستراتيجيات التسويق فى محطة الحاويات بميناء رجائى فى إيران. وقد توصلت الدراسة إلى العديد من النتائج كان من أبرزها أن إستراتيجية الميناء وسياسته والإمدادات بداخله والظروف المحيطة به تؤثر فى تحقيق ميزة تتافسية . צ - دراسة حسني عابدين محمد عابدين (10 ( ب): بعنوان: مدخل التكلفة

المستهدفة لاعم القدرة التنافسية لمصانع الباطون الجاهز بقطاع غزة - دراسة ميدانية تهدف الدراسة الإلى التعرف على مدى تطبيق مدخل التكلفة المستهدفة لدعم القدرة التتافسية

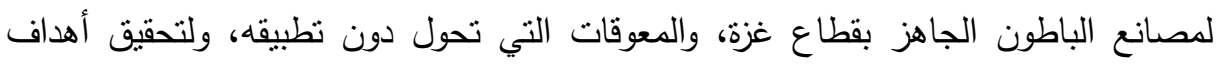
الدراسة واختبار فرضياتها، اعتمدت الدراسة على المنهج الوصفي التحليلي، وصمدت استبانة الاستطلاع أراء أفراد العينة بعدد (؟)(spss) - الإحصائي

وقد خلصت الاراسة إلى عدة نتائج أهمها: إن مصانع الباطون الجاهز في قطاع غزة نطبق

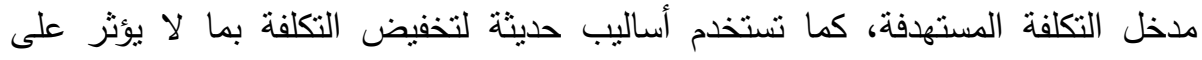
الجودة، ويؤدى ذللك الى تطوير المنتجات ودعم القدرة التنافسية، لكن توجد معوقات تحد من التطبيق منها: الظروف السياسية والاقتصادية السائدة، وقلة المعلومات التفصيلية اللازمة لتطبيق مدخل التكلفة المستهدفة، وقد أوصت الدراسة بالعمل على إزالة المعوقات التي تحد من تطبيق مدخل التكلفة المستهدفة في مصانع الباطون الجاهز بقطاع غزة سواء الداخلية منها أو الخارجية. 


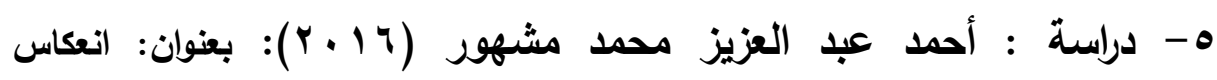

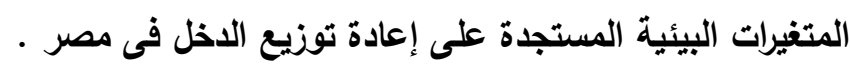

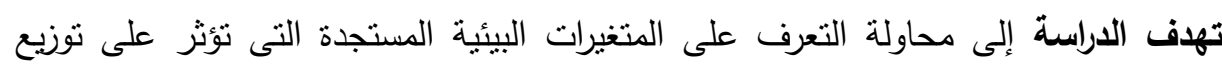

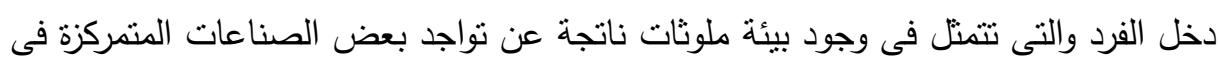

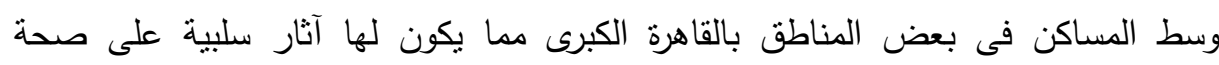

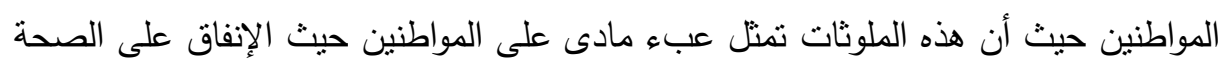

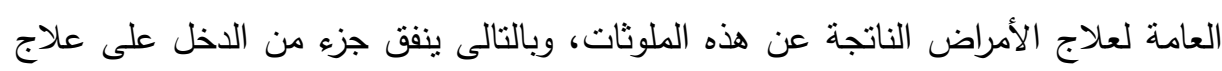

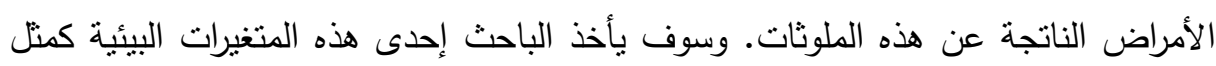

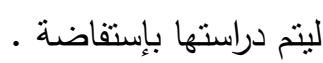
وقد توصلت الاراسة إلى أن ظاهرة الإحتباس الحرارى ناتجة عن سوء إستخدام الأفراد للموارد البيئة وتسبب ضرراً على البيئة. تعليق عام على الدراسـات السـابقة: بعد استعراض الدراسات السابقة العربية والأجنبية سواء

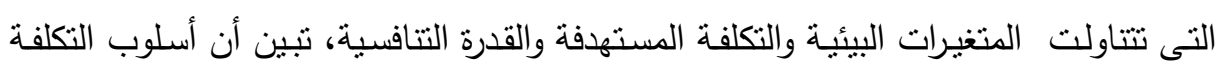

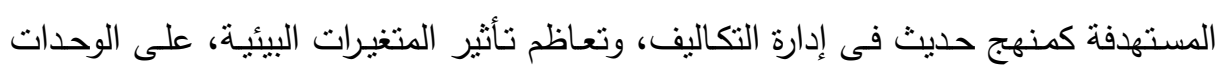
الاقتصادية.

اتفقت الباحثة مع معظم الدراسات السابقة بأن منهج التكلفة المستهدفة من أفضل الأساليب فى مجال خفض التكاليف وتحقيق القدرة التتافسية.

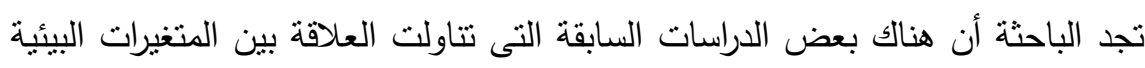

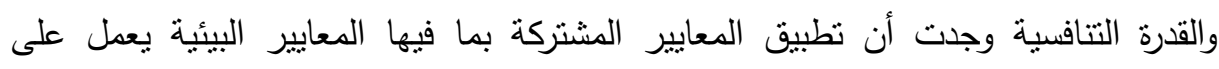
تحسين الكفاءة وتسهيل التجارة وهذا بدوره يزيد من القدرة التنافسية

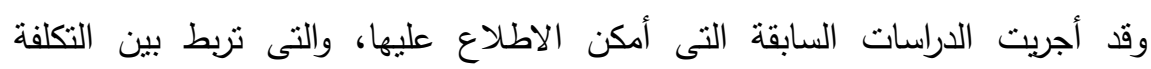

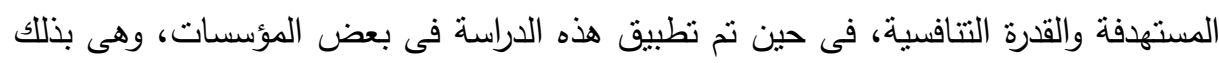

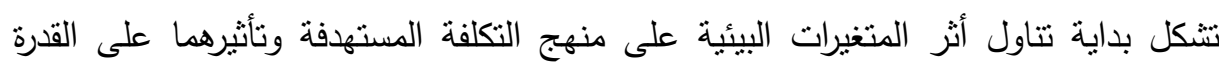
التنافسية للمؤسسات. 
وما يميز هذه الدراسة عن سابقاتها من الدراسات والأبحاث هى إنها تبحث فى جانب

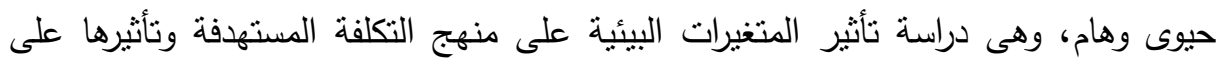
القدرة التتافسية، وتتمنل فى المتغيرات البيئية وأسلوب التكلفة المستهدفة والأثر المحتمل لهما لهائه على زيادة القدرة التتافسية، لذلك جاءت هذه الدراسة مكملة للنقص فى الدراسات السابقة.

\section{الإسار النظلغى اللهيهي}

المتغيرات البيئية ومنهج التكلفة المستهدفة: هناك عدة عوامل متتوعة تؤثر فى السلوك الثرائى والإستهلاكى للأفراد ينتمى بعضها إلى البيئة الخارجية المحيطة بالمستهلك،

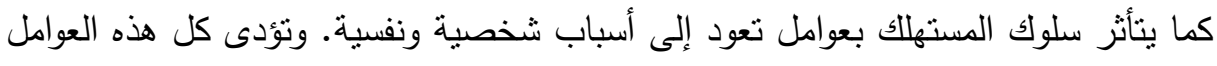
إلى تشكيل النمط الاستهلاكى للفرد، كما تحدد اختياراته وسلوكه خلال المراحل المختلفة لعملية اتخاذ القرار الثرائى. المتغيرات البيئية ومنهج التكلفة المستهدفة: أولاً: المتغيرات البيئية: المفهوم والأنواع.

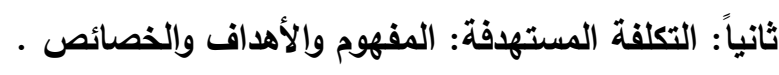

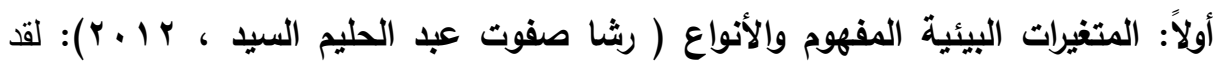

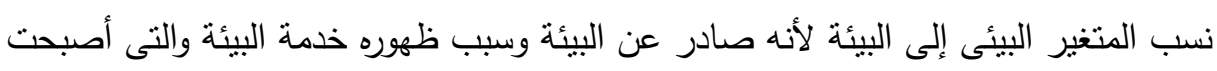
محل اهتمام العلماء من مختلف المجالات فى الأونة المعاصرة، أى أن المتغير البيئى هو أداة تستخدم للحفاظ على البيئة من قبل المتخصصين كل في مجل مجاله.

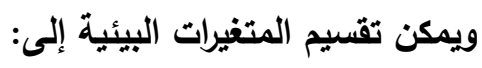

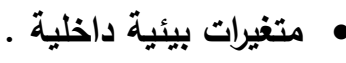
ا- هيكل المنشأة

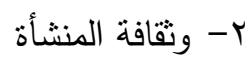

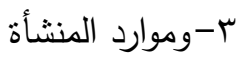




\section{• متغيرات بيئية خارجية.}

1- المتغيرات الإقتصادية Economic Variables

Y كocial and Cultural Variables المتغيرات الاجتماعية والتقافية الإيه

r- الكتغيرات التكنولوجية Technological Variables

Legal and Political Variables المتغيرات السياسية والحكومية والقانونية

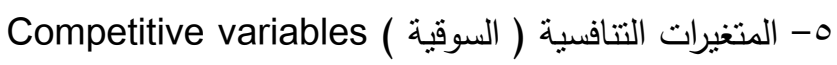

$$
\text { ج- المتغيرات الدولية }
$$

ثانياً: التكلفة المستهدفة : المفهوم والأهداف والخطوات الاتهة

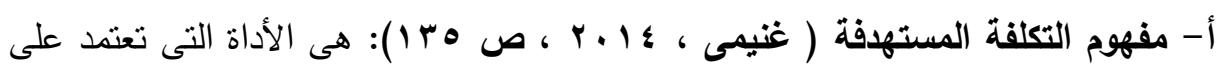

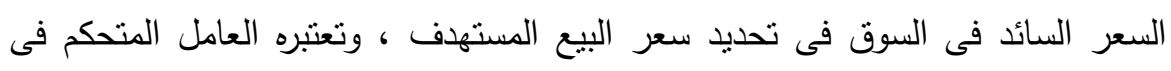

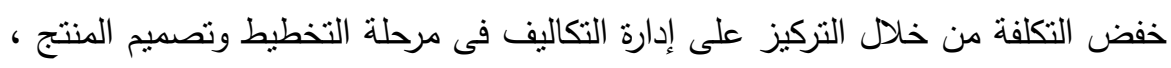

مع مراعاة العلاقة المباشرة بين الوضع التنافسى فى السوق وأرباح المنشأة وعملية إدارة

$$
\text { التكاليف فى الأجل الطويل. }
$$

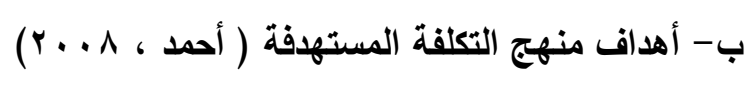

1-تحديد تكاليف المنتج المستهدفة أى التكلفة التتافسية المستمدة من السوق الخدارة الخدارجى ومقارنتها بتكلفة المنتج لما يكفل تحقيق الخفض المستمر وزيادة فاعلية تصميم المنتج وتطويره

r-تحقيق أهداف الإدارة العليا من أرباح ومنافسة على الددى الطويل فى ظل التهني التغيرات

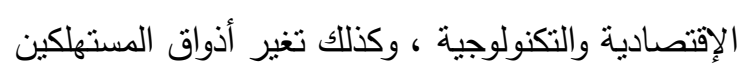

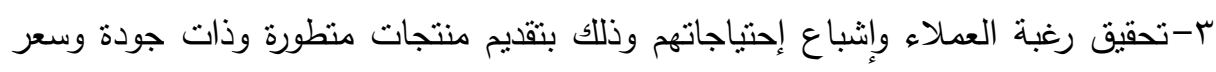

$$
\text { مناسبين لضمان الاستمرارية والتنافسية }
$$

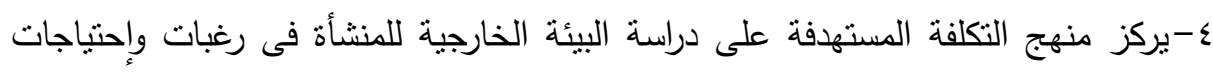

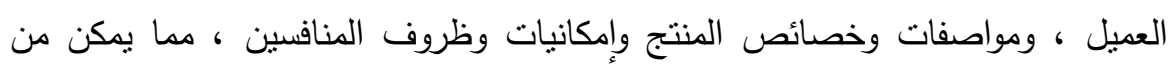

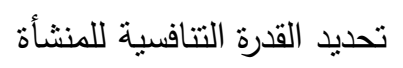




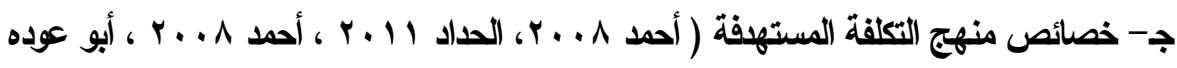

$(r+1$.

ا-تعتمد التكاليف المستهدفة على فرض وجود مستويات عالية جداً من التعاون بين الإدارات

والتعاون بين الأقسام المختلفة لتحقيق التكلفة المستهدفة .

r-تقود أسعار السوق قرارات التكلفة ، حيث إن أسعار السوق تستخدم فى تحديد التكلفة

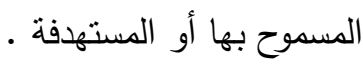

r-تستخدم التكلفة المستهدفة كأداة للرقابة كونها تطبق فى مرحلة التخطيط والتصميم للمنتجات، والتى تتميز بها عن التكاليف المعيارية التى تطبق عند مرحلة الإنتاج. ع-يتم إستخدام بعض أساليب علم الإدارة فى تحديد التكاليف المستهدفة لأن الأهداف الإدارية

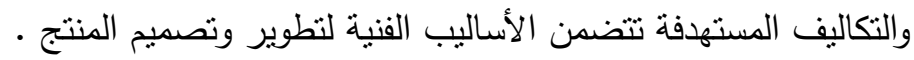

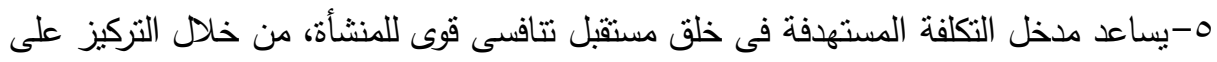
الإدارة الموجهة بالسوق.

צ-تتاسب التكلفة المستهدفة المنتجات التى تتصف بقصر دورة حياتها أكثر من المنتجات التى لها دورة حياة طويلة ، وذلك لسهولة تحديد تكاليف المدخلات بدقة فى الأجل القصير ، وسرعة التعرف على ردود فعل العملاء تجاه المنتج الجديد .

\section{العلاقة بين المتغيرات البيئية فى ظل استخدام التكلفة المستهذفة وزيادة القرة} التنافسية للوحدة الاقتصادية: تتبع أهمية القدرة النتافسية من كونها تعمل على نوفير البيئة التتافسية الملائمة لتحقيق كفاءة أكبر في تخصيص الموارد ، بالإضافة إلى أن القدرة التتافسية

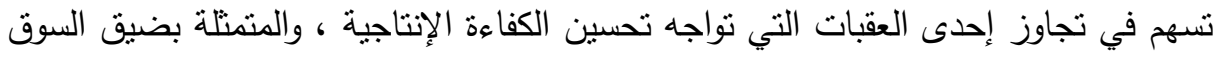

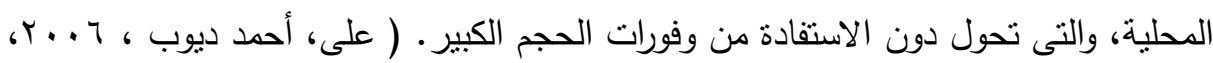

أولاً : القدرة التنافسية (مفهوم - التطور - الأسباب - الأبعاد ). ثانياً : العلاقة بين المتغيرات البيئية والتكاليف المستهدفة . ثالثاً : العلاقة بين المتغيرات البيئية والقدرة التنافسية. 


$$
\text { أولاً : القدرة التنافسية (مفهوم - التظور - الأسباب - الأبعاد ). }
$$

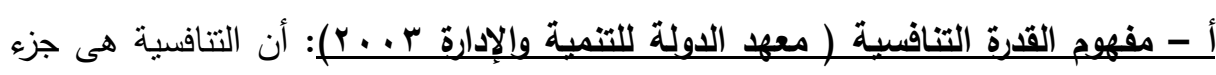
من إقتصاد المعرفة الذى يحلل الوقائع والسياسات والتى تحدد قدرة الدولة على إيجاد بيئة مناسبة والحفاظ عليها، والتى تساعدها على توليد القيمة المضافة المستدامة لمؤسساتها

$$
\text { وزيادة الإزدهار لشعوبها. }
$$

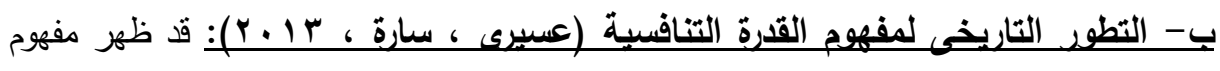

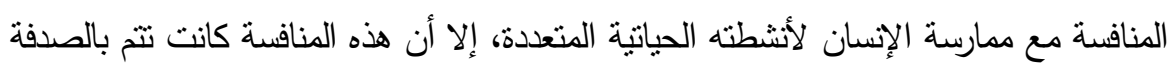

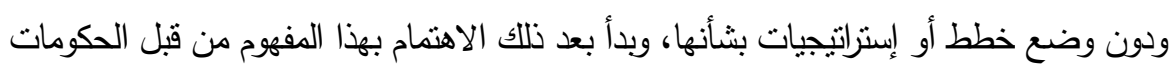

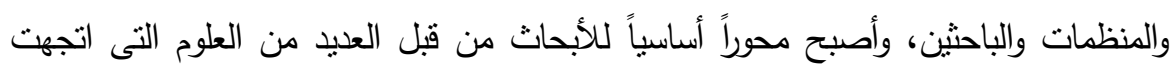
للتعرف على أسباب النجاح والفشل لبعض الدول أو المنظمات أو الجماعات ، وتلى ذلك ظهور

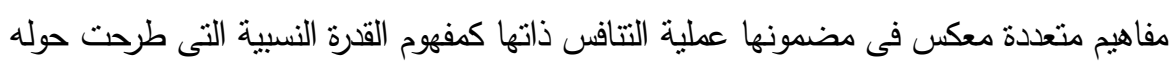

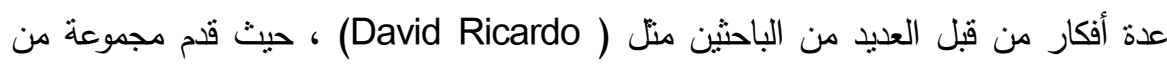

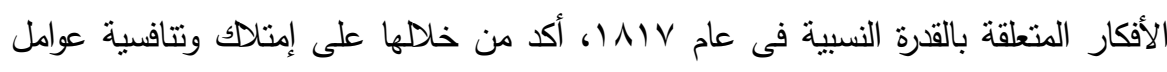

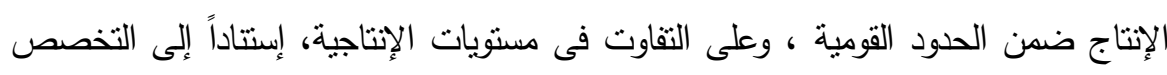
والتبادل التجارى.

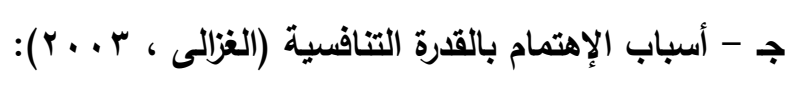

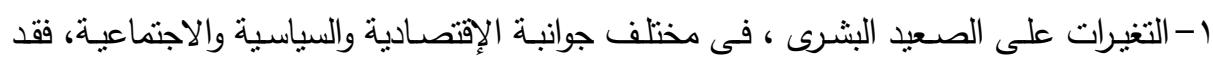

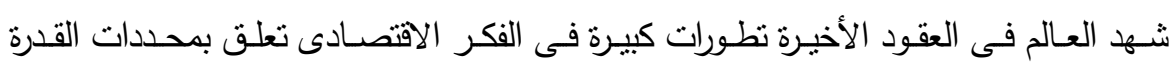

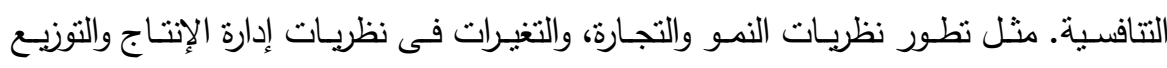
والتخزين ، وظهور نظرية إدارة الجودة الثاملة TOM والتتافسية عوضاً عن المنافسة.

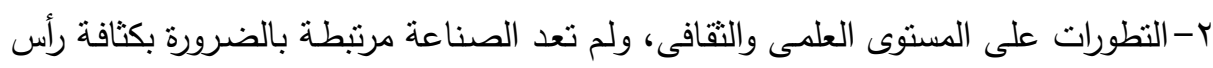
المال بقدر ارتباطها بالمعرفة ومهارات العاملين والإدارة الكفوةها. r-التطورات السياسية والتوجهات الجديدة وظهور عالم القطب الواحد، وتعزيز دور المؤسسات الدولية، مما يؤدى إلى إنعكاسات على مختلف الأنشطة، مثل الإنتاج والحوكمة والمشاركة

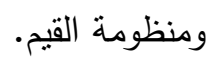




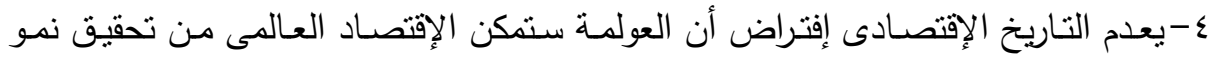

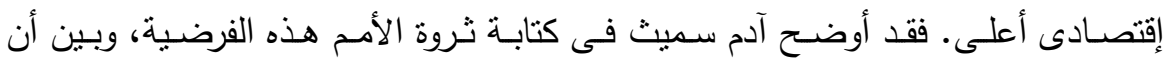

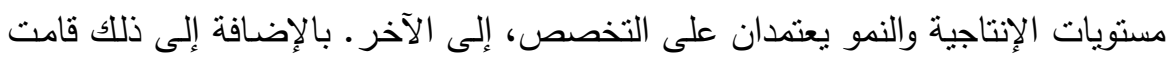
عدة منظمات إقليمية ودولية بتقديم تعريف للتنافسية حسب منظورها ورؤيتيتها وأهدافها. د- أبعـاد القـدرة التنافسية والتفـوق التنافسى : الجودة - الإبداع - الإحتفـاظ بـالعملاء -

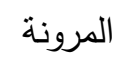

\section{إجبراعاهت التصواسة}

تهذف الدراسة إلى إختبار فروض ، والوصول إلى المتغيرات التى تؤدى لزيادة القدرة التتافسية

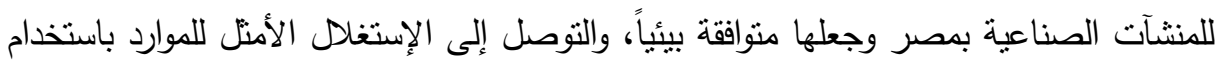
التخطيط البيئى والتتسيق مع أسلوب التكلفة المستهدفة.

\section{أسالآمبع القواسلة}

قام الباحثون بتصميم قائمة استقصاء تتقق مع أهداف الدراسة، وتساعد في اختبار فروضها، وقد اشتملت على بيانات شخصية (العمر، المؤهل الدراسي، الوظيفة الحالية، عدد اهدية سنوات الخبرة، والخصص العلمي) وثلاثة محاور بحثية هي: المحور الأول: المتغيرات البيئية المحور الثاني: منهج التكلفة المستهدفة المحور الثالث: القدرة النتافسية

قام الباحثون بعرض قائمة الاستقصاء على المختصين لتحكيمها، وأخذ الموافقة على توزبعها، واستخدامها في جمع بيانات الدراسة. قام الباحثون بتوزيع القائمة على عينة استطلاعية للتأكد من وضوح الأسئلة، ومعرفة

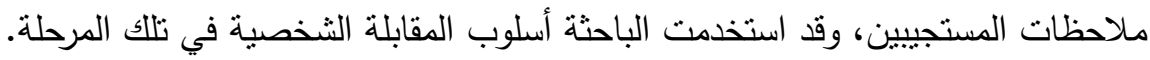
قامت الباحثة بصياغة قائمة الاستقصاء في شكلها النهائي، بعد أخذ ملاحظات

$$
\text { مستجيبي العينة الاستطلاعية في الاعنبار . }
$$


قام الباحثون بتوزيع القائمة على عينة الدراسة، وبعد إعطائهم الوقت الكافي لاستيفائها،

$$
\text { قامت بجمعها ومراجعتها. }
$$

واشتملت قائمة الإستقصاء على V \ـ سؤال وتم عمل حساب الصدق والثبات للأداة كما يلى:

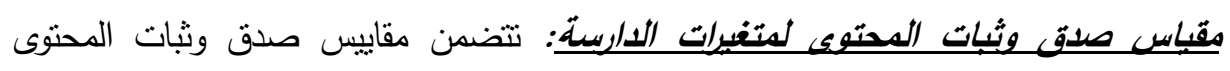

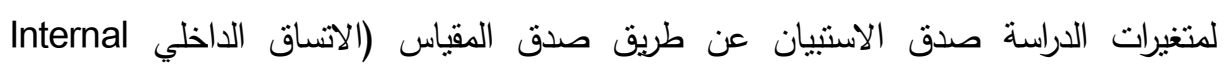

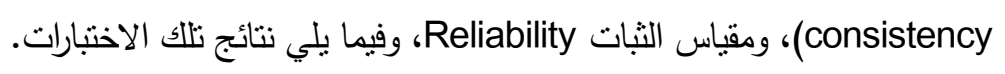

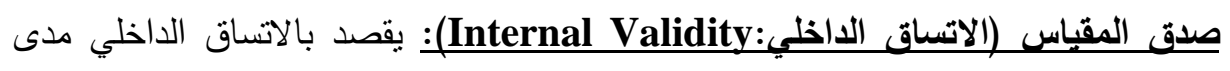

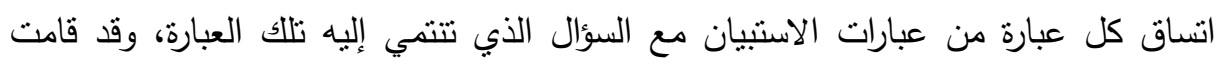

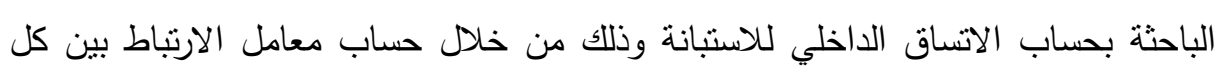
عبارة من عبارات الاستبانة، والمتوسط العام السؤال الذي تتنمي إليه تلك العبات العبارة مقاييس الثبات: Reliability: قامت الباحثة بقياس ثبات المحتوى لمتغيرات الدراسة باستخدام معامل الثبات Cronbatch alpha) وذلك لقياس مدى اعتمادية Reliability)

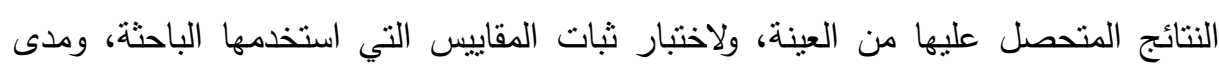

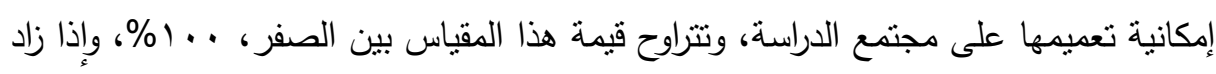
هذه المقياس عن • ب\% أمكن الإعتماد على نتائج الدراسة، وفيما يلي تطبيق هذا المقياس على أبعاد الدراسة.

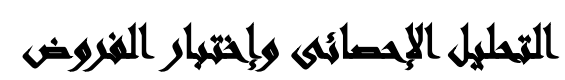

وفيما يلى تطبيق هذه الأساليب الإحصائية على متغيرات الدراسة: قامت الباحثة بإجراء اختبار الاعنمادية Reliability للتاكد من ثنات الاستجابات، وإجراء النتاسق الداخلي للتنأكد من تمثنيل

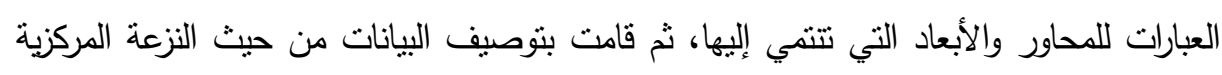
والتشتت، وانتهاء بإجراء الإحصاء التحليلي لاختبار الفرضيات، والتوصل إلى لإدي النتائج. مجتمع الاراسة: يتمثل مجتمع الدراسة في العاملين في المنشآت الصناعية المصرية بالقاهرة الكبرى، وخاصة ذوب الاهنمام بمجال البيئة. 
عينة الاراسة: وقد قامت الباحثة بزيارة عدد من المنشآت الصناعية المصرية عينة عددها ؟ قائمة إستقصاء من مجتمع الدراسة خلال عام 1 1 ـ r.

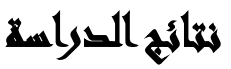

اختبار الفرض الأول: توجد علاقة ذات دلالة إحصائية بين المتغيرات البيئية والتكلفة

المستهذفة.

وقد نم اختبار هذا الفرض من خلال دراسة علاقات الارتباط والانحدار بين المتغير

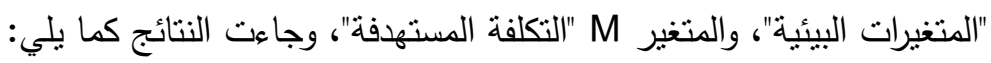
علاقات الارتباط والاتحدار بين المتغيرات البيئية والتكلفة المستهدفة: بتطبيق أسلوب الارتباط والانحدار بين المتغيرات البيئية والتكلفة المستهدفة جاءت النتائج كما يوضحها

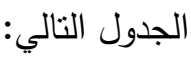

جدول( (1): نتائج الارتباط والانحدار بين المتغيرات البيئية والتكلفة المستهدفة

\begin{tabular}{|c|c|c|c|c|c|c|c|}
\hline & \multicolumn{3}{|c|}{ المتغير التابع: التكلفة المستهدفة } & \multicolumn{4}{|c|}{ المتغير المستقل: المتغيرات البيئية } \\
\hline المستوية & الميمسة T T & المعاملة & 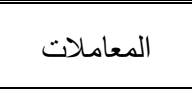 & مستوى & & معامل & معامل \\
\hline$\cdot, \ldots$ & $\lambda, \wedge r \varepsilon$ & $1,1 \times 0$ & ثنابت الانحدار & & 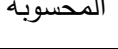 & $\mathrm{R}^{2}$ & $\mathrm{R}$ \\
\hline & $r \varepsilon, 00$ & $\cdot, \wedge 79$ & معامل الانحدار & & $7 \cdot r, 9$ & $\cdot, \wedge \uparrow \wedge$ & (**)., ( \\
\hline
\end{tabular}

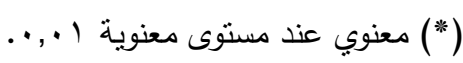

يتضح من الجدول السابق رقم (1) ما يلي:

- أظهرت نتائج الارتباط الخطي وجود علاقة ارتباط طردية ذات دلالة معنوية بين المتغيرات

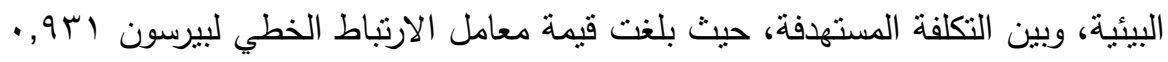

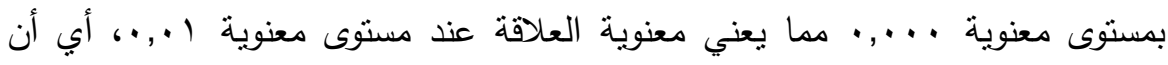

تحسن المتغيرات البيئية يصاحبه تحسن في التكلفة المستهدفة.

- بعد تقدير معالم نموذج الانحدار يمكن صياغة معادلة الاتحدار بالثكل التالي:

$M=1.175+0.869 * X+\varepsilon$

حيث: M التكلفة المستهدفة، X المتغيرات البيئية، ع الخطأ العشوائي.

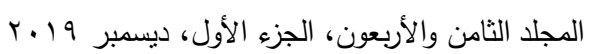




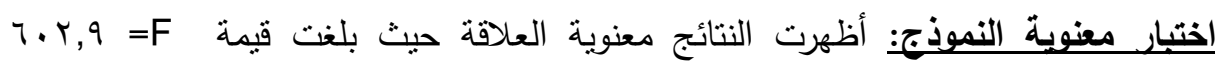

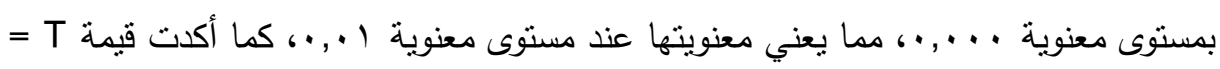

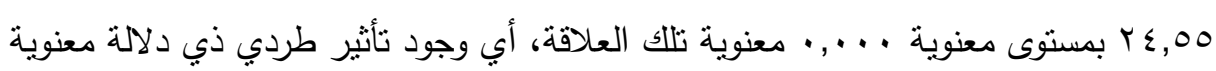

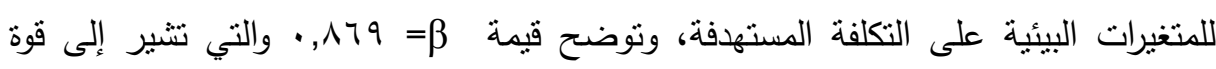
واتجاه التأثير ، أي أن تحسن المتغيرات البيئية بدرجة واحدة يتبعها تحسن في التكلفة المستهدفة فئة

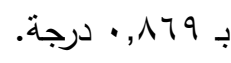

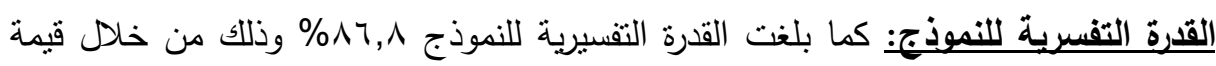

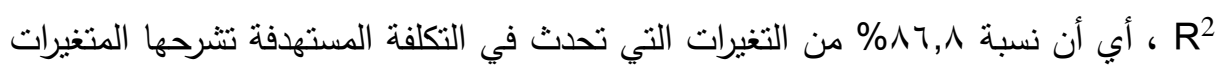

اختبار الفرض الثاني: توجد علاقة ذات دلالة إحصائية بين المتغيرات البيئية والقدرة

التنافسية.

وقد تم اختبار هذا الفرض من خلال دراسة علاقات الارتباط والانحدار بين المتغير "المتغيرات البيئية"، والمتغير Y "القدرة التتافسية"، وجاءت النتائج كما يلي:

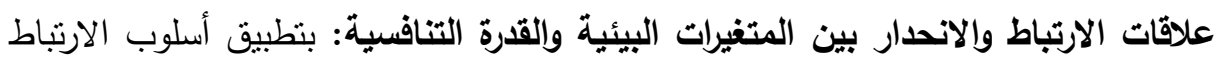

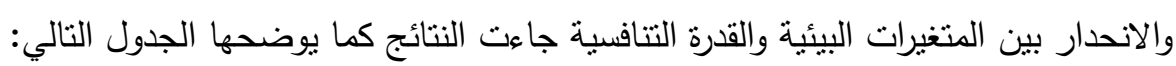

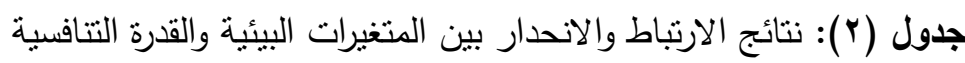

\begin{tabular}{|c|c|c|c|c|c|c|c|}
\hline \multicolumn{4}{|c|}{ المتغير التابع: القدرة التنافسية } & \multicolumn{4}{|c|}{ المتغير المستقل: المتغيرات البيئية } \\
\hline المعنوية & 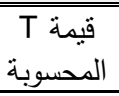 & المعامل & المعاملات & مستوى & $\mathrm{F}$ & التحديد & الارنباط معامل \\
\hline$\cdot, \cdots$ & $0, Y V-$ & $1, .07-$ & ثابت الانحدار م & & & R2 & $\mathrm{R}$ \\
\hline$\cdot, \cdots$ & $r$ r & $1,1 \cdot 1$ & معامل الانحدار & $\cdot, \cdots$ & oV $\varepsilon, r$ & $\cdot, \wedge \pi r$ & $(* *) \cdot, 9 \curlyvee \wedge$ \\
\hline
\end{tabular}

(*) معنوي عند مستوى معنوية ا +,.•. يتضح من الجدول السابق رقم (r) ما يلي: - أظهرت نتائج الارتباط الخطي وجود علاقة ارتباط طردية ذات دلالة معنوية بين المتغيرات

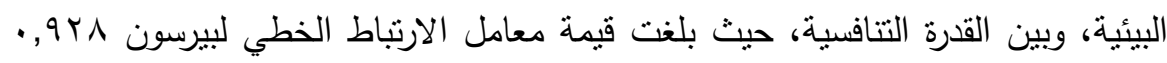


بمستوى معنوية ..., .. مما بعني معنوية العلاقة عند مستوى معنوية ا.,.•، أي أن تحسن المتغيرات البيئية يصاحبه تحسن في القدرة التتافسية. - بعد تقدير معالم نموذج الانحدار يمكن صياغة معادلة الانحدار بالثكل النالي: $\mathrm{Y}=-1.056+1.101 * \mathrm{X}+\varepsilon$

$$
\text { القدرة التتافية، X } \quad \text { X }
$$

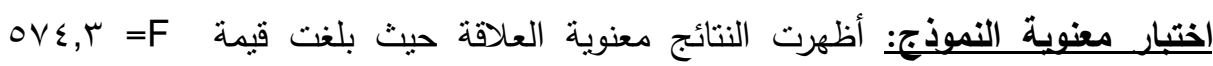

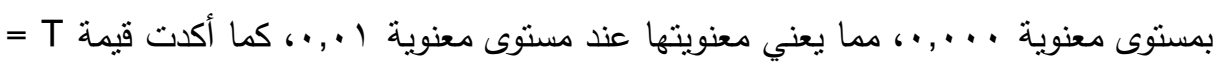

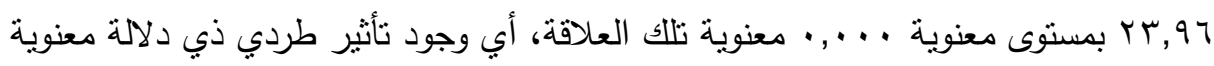

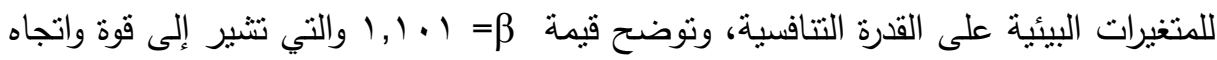
التأثنر، أي أن تحسن المتغيرات البيئية بدرجة واحدة يتبعها تحسن في القدرة التنافسية بـ البها

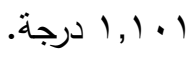

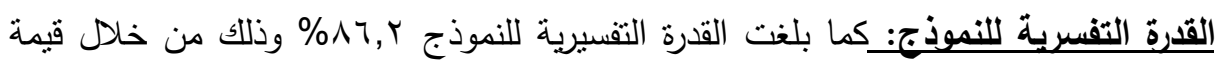

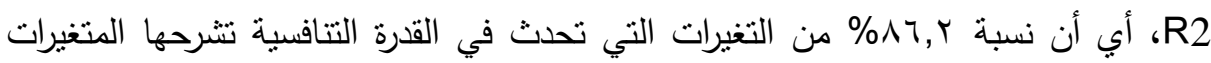

$$
\text { نخلص من ذلك إلى قبول الفرض الثاني للباحث. }
$$

اختبار الفرض الثالث: توجد علاقة ذات دلالة إحصائية بين التكلفة المستهذفة والقدرة

وقد نم اختبار هذا الفرض من خلال دراسة علاقات الارتباط والانحدار بين المتغير

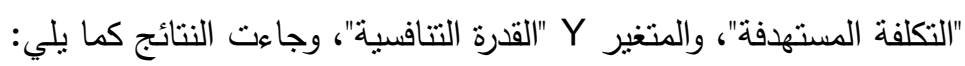
علاقات الارتباط والانحدار بين التكلفة المستهدفة والقدرة التنافسي: بتطبيق أسلوب الارتباط والانحدار بين التكلفة المستهدفة والقدرة التتافية جاءت النتائج كما يوضحها الجدول التالي: 
جدول (ץ): نتائج الارتباط والاتحدار بين التكلفة المستهدفة والقدرة التتافسية

\begin{tabular}{|c|c|c|c|c|c|c|c|}
\hline \multicolumn{5}{|c|}{ المتغير التابع: القدرة التنافسية } & \multicolumn{3}{|c|}{ المتغير المستقل: التكلفة المستهـفة } \\
\hline مستوى & المحسوبة T & المعامل & كاملات & \multirow{2}{*}{ المعنوية } & \multirow{2}{*}{$\begin{array}{c}\text { F } \\
\text { المحسوبة }\end{array}$} & \multirow{2}{*}{$\begin{array}{l}\text { التحديد } \\
\text { R }^{2}\end{array}$} & \multirow{2}{*}{$\begin{array}{c}\text { الارتباط } \\
\text { R } \\
\text { R }\end{array}$} \\
\hline ,, & $\varepsilon, \Gamma$ & $\cdot$, Or & ثابت الانحدار & & & & \\
\hline & T1, & אדוג, • & معامل الانحدار & & $97 \varepsilon, V$ & •, 9וर & ("*)., 900 \\
\hline
\end{tabular}

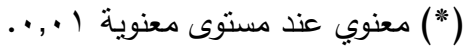

$$
\text { يتضح من الجدول السابق رقم (r) ما يلي: }
$$

- أظهرت نتائج الارتباط الخطي وجود علاقة ارتباط طردية ذات دلالة معنوية بين التكلفة المستهدفة، وبين القدرة التنافسية، حيث بلغت قيمة معامل الارتباط الخطي لبيرسون

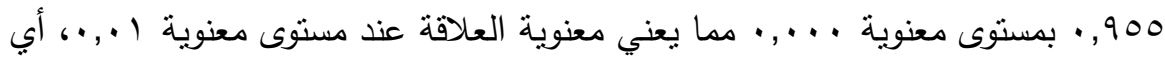
أن تحسن التكلفة المستهدفة يصاحبه تحسن في القدرة التنافسية. - بعد تقدير معالم نموذج الانحدار يمكن صياغة معادلة الانحدار بالثكل التالي: $\mathrm{Y}=0.531+0.863 * \mathrm{M}+\varepsilon$

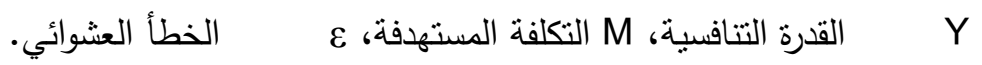

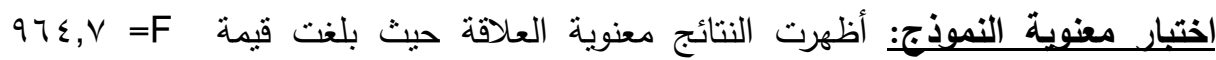

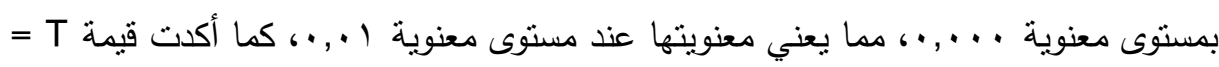

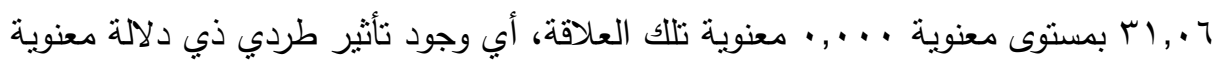
للمتغيرات البيئية على القدرة التنافسية، وتوضح قيمة م= سדیر, · والتي تشير إلى قوة واتجاه

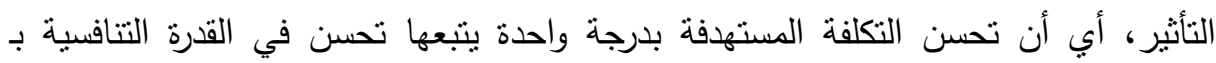

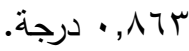
القدرة التفسرية للنموذج: كما بلغت القدرة التقسيرية للنموذج r, ب 9 \% وذللك من خلال قيمة R2 أي أن نسبة r, ا9\% من التغيرات التي تحدث في القدرة التتافسية تشرحها التكلفة 


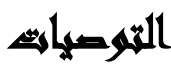

1. الاهتمام بالمتغيرات الفنية واستخدام تكنولوجيا حديثة ومتطورة، وتطوير وسائل التصنيع •

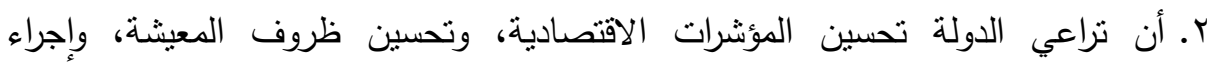
الدراسات العلمية التي تساعد على تحديد المؤشرات الاقتصادية بدقة. r. أن تحفز الدولة الصناعات صديقة البيئة عن طريق تفعيل قانون حماية البيئة من التلوث وقوانين منح التسهيلات والقروض والإعفاءات. ع. متابعة المتغيرات الدولية مثل التجمعات الاقتصادية والعلاقات الدولية بين حكومات الدول المختلفة حتى نتمكن من دراسة الأسواق المنافسة.

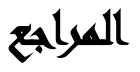

أحمد عبد العزيز محمد مشهور (T (1): " إنعكاس المتغيرات البيئية المستجدة على إعادة

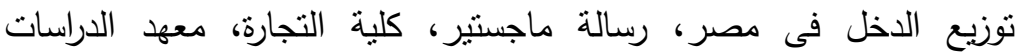

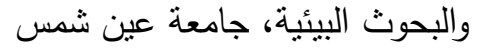

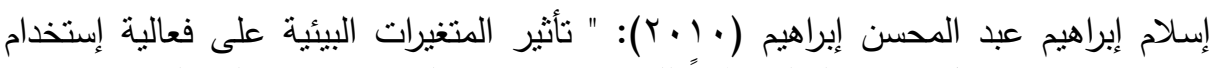

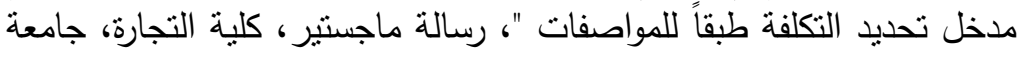

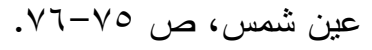

حسني عابدين محمد عابدين: مدخل التكلفة المستهدفة لدعم القدرة التتافسية لمصانع الباطون

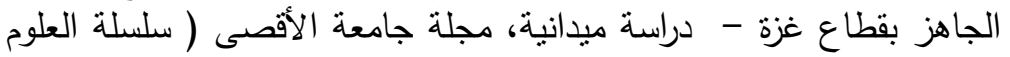

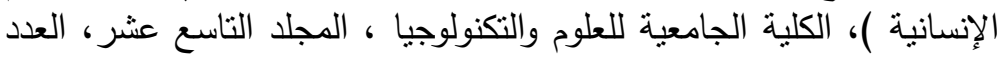

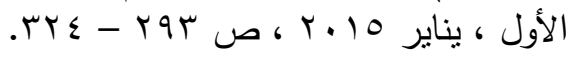

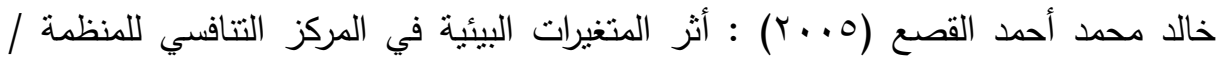

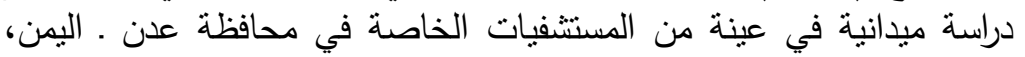

$$
\text { رسالة ماجسنتير }
$$

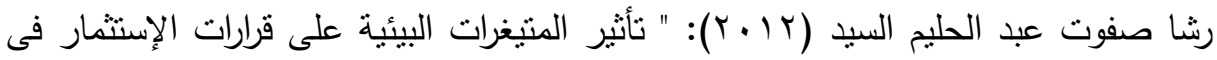

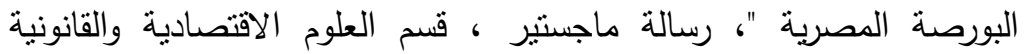

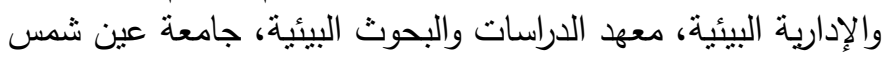

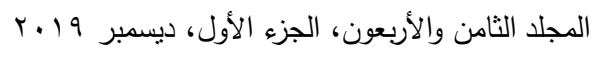




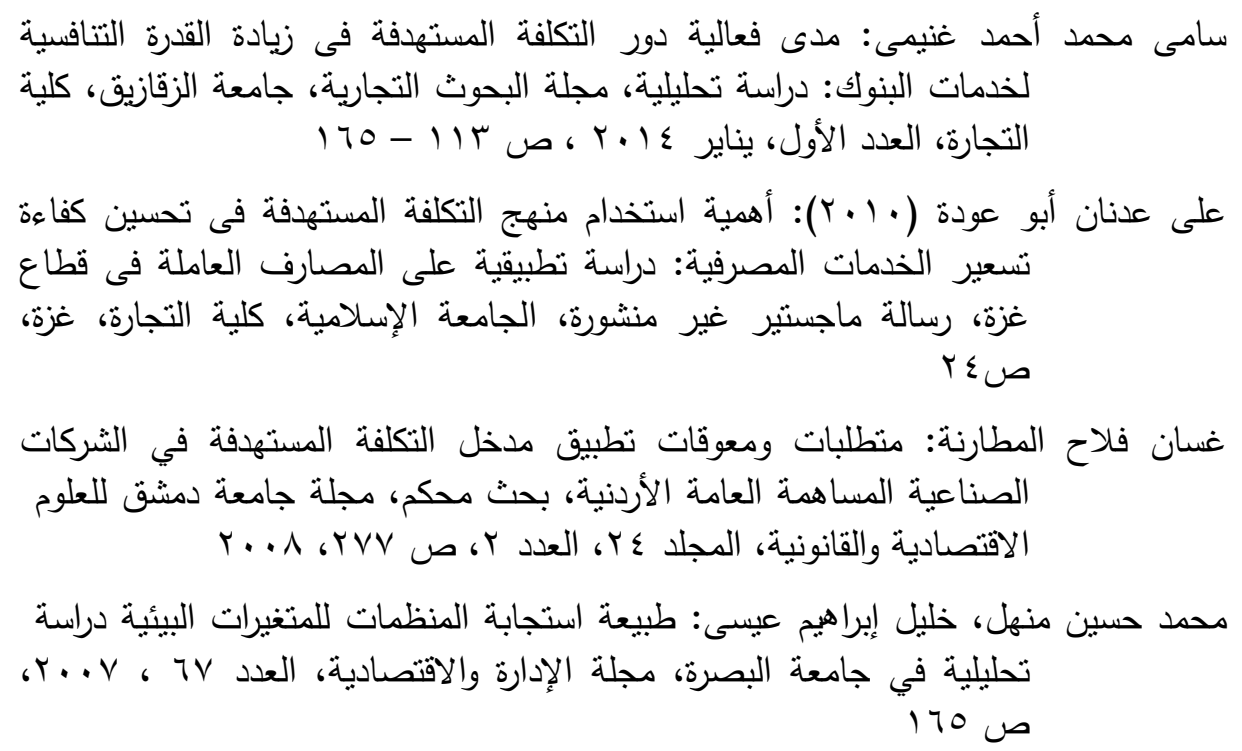

Cheraghi, Hossein; Khaligh, Alireza Abdolhosseini \& Naderi, Abbass, (2012), "Gaining Competitive Advantage through Marketing Strategies in Container Terminal: A Case Study on Shahid Rajaee Port in Iran", Intemational Business Research, Vol. 5, No. 2: 179 - 191. 
مجلة العلوم البيئية

معهد الدراسات والبحوث البيئية - جامعة عين شمس لئس

\title{
THE EFFECT OF ENVIRONMENTAL VARIABLES \\ ON USING TARGETED COST METHODOLOGY TO \\ INCREASE COMPETITIVENESS \\ A FIELD STUDY
}

[12]

\author{
Ebtihal B. Hassan $^{(1)}$; Samas k. musaa ${ }^{(2)}$ \\ and Kareem M. Ali ${ }^{(2)}$
}

1) Post Gard. Institute of Environmental Studies and Research, Ain Shams University 2) Faculty of Commerce, Ain Shams University

\begin{abstract}
The study seeks to identify the environmental variables that affect the target cost and competitiveness and test the relationship between environmental variables and target cost, Also test the relationship between environmental variables and competitiveness, And test the relationship between the use of the target cost approach and competitiveness, Through a survey form distributed to a sample of (94) specialists to arbitrate a group of companies with industrial activity in Greater Cairo, using the descriptive and analytical method, the results showed that there is a statistically significant relationship to the impact of environmental variables on the use of the target cost approach to increase competitiveness.

The study recommended:

1. Attention to reduce costs while maintaining quality throughout the production process

2. The pricing of the product should be based on scientific studies of the market in all its aspects.

3. To study the obstacles and problems that prevent the application of the target cost approach, Achieving appropriate quality, excellence and innovation in products to suit the wishes of customers, and it faces stiff competition in the markets.
\end{abstract}

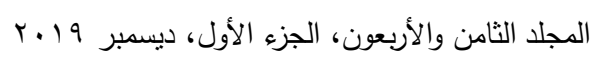

